\title{
Bronchial collateral circulation in experimental stenosis of the pulmonary artery
}

\author{
P. HE I M B U R G \\ From the Nuffield Unit of Clinical Physiology, Postgraduate Medical School, Hammersmith Hospital, \\ London W.12
}

The bronchial circulation normally represents only $1 \%$ or less of the cardiac output (Bruner and Schmidt, 1947 ; Salisbury, Weil, and State, 1957). In several diseases of the heart and lungs, however, bronchial vessels can undergo impressive changes. They become dilated and increased in number. This process may affect the arterial or venous side of the bronchial vascular system according to the character of the disease. Collateral vessels between the bronchial and pulmonary circulation are also involved, as is frequently shown in anatomical studies (Ferguson, Kobilak, and Deitrick, 1944 ; Liebow, Hales, and Lindskog, 1949 ; Marchand, Gilroy, and Wilson, 1950 ; Liebow, 1953 ; Schoenmackers, 1960 ; Florange, 1960 ; Schoenmackers, 1963).

Three factors are implicated in the development of an increased bronchial circulation: (1) heart disease with abnormal pulmonary circulation; (2) chronic infection of the lung ; and (3) bronchial neoplasm. Whereas both chronic infection and neoplasm are localized to only a part of the lung, heart disease always affects the whole lung and thus assumes increased haemodynamic importance. Pulmonary atresia with ventricular septal defect, for example, is incompatible with life unless the bronchial collateral circulation is adequate.

Animal experiments indicate that approximately two-thirds of the bronchial arterial flow drains into the pulmonary circulation (Berry and Daly, 1931). Blood flow in the opposite direction, from the pulmonary to the bronchial circulation, either does not occur or is exceedingly small in normal dogs (Heimburg, Ochwadt, and Schoedel, 1961 ; Schoedel, Baltzer, Gade, and Piiper, 1961; Schoedel and Heimburg, 1962). The relation between bronchial and pulmonary circulation is shown schematically in Figure 1.

Collateral flow depends on the pressure on either side of the anastomotic vessel and on vascular resistance. Considerable evidence exists, I Present address: Medizinische Universitäts Klinik, Göttingen,
Germany. however, indicating that blood is also shunted at capillary level.

This paper is concerned with the bronchial collateral flow in pulmonary arterial stenosis, which is the simplest form of malformation in which the development of collateral vessels occurs.

\section{METHOD}

The experiments were carried out on 11 mongrel dogs, weighing from 8 to $13 \mathrm{~kg}$., anaesthetized with pentothal $(30 \mathrm{mg} . / \mathrm{kg}$.). At the first operation about six to eight weeks after birth the main pulmonary artery in seven dogs was encircled with linen tape without causing acute stenosis. These dogs developed relative pulmonary stenosis while growing up. In another two dogs the right pulmonary artery alone was encircled from a left-sided incision and mildly stenosed in order to get more severe stenosis with time. Finally, in two dogs the pulmonary artery of the right lower lobe was stenosed by suturing a $1 \mathrm{~mm}$. diameter teflon tube into the vessel. One was found to be thrombosed later, and one was still patent. The dogs were examined regularly for clinical symptoms of stenosis, such as systolic murmurs and right heart hypertrophy.

After three to four months the dogs were subjected to an experimental procedure similar to that described

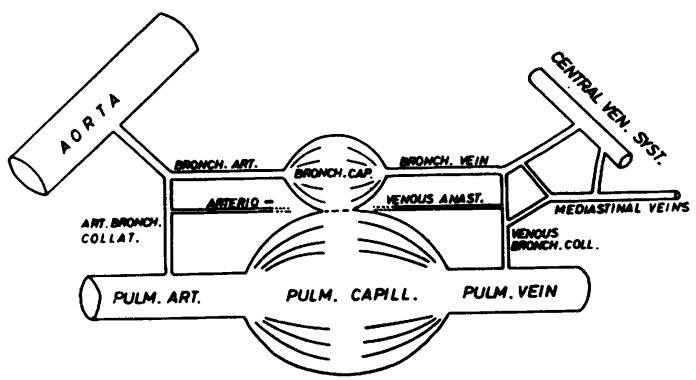

FIG. 1. The circulation of the lung. There are vascular connexions between the bronchial artery and the pulmonary artery and between the pulmonary vein and the bronchial vein. In addition direct arterio-venous shunts have been demonstrated. The bronchial veins anastomose with mediastinal veins and the latter are in connexion with the veins of the oesophagus. 
previously (Heimburg et al., 1961). After right thoracotomy the dogs were ventilated by a Beaver respirator. The middle and retrocardiac lobes were removed. The right lower lobe, which represents about one third of the total lung in the dog, was perfused with blood as shown in Figure 2.

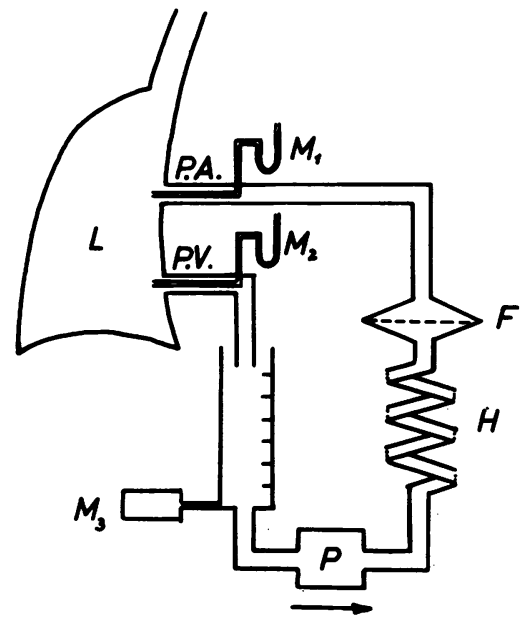

FG. 2. Experimental set-up for the estimation of bronchial collateral flow. $P . A .=$ pulmonary urtery; P.V.= pulmonary vein; $L=$ lung lobe; $P=$ punip; $H=$ heat exchanger; $F=$ filter; $M_{1}, M_{2}$ and $M_{3}=$ manometers. For details see text.

Pulmonary venous blood drained freely into a measuring cylinder. It was then pumped back into the pulmonary artery by a sigmamotor pump (P), passing first through a heat exchanger $(\mathrm{H})$, and a filter (F). Pulmonary arterial and venous pressures were measured by two water manometers $\left(\mathbf{M}_{1}\right.$ and $\left.\mathbf{M}_{2}\right)$ connected to the artery and vein. The bronchial collateral flow of the lobe was measured by the change of blood level per time interval within the cylinder, which could be recorded by means of an N.E.P. ${ }^{1}$ pressure transducer $\left(\mathbf{M}_{3}\right)$.

In order to determine the collateral inflow into the experimental circuit and outflow to the systemic circulation, ${ }^{51} \mathrm{Cr}$-labelled red cells were added to the circuit (Method, see Mollison and Veall, 1955). Collateral outflow per unit time may be calculated by the equation:

$$
\dot{\mathrm{Q}}_{\text {outflow }}=2 \frac{\mathrm{V}_{1} \mathrm{C}_{1}-\mathrm{V}_{2} \mathrm{C}_{2}}{\mathrm{C}_{1}+\mathrm{C}_{2}}
$$

$V_{1}$ and $C_{1}$ are the volume of the circuit and the counting rate per $\mathrm{ml}$. of blood at the beginning; $\mathrm{V}_{2}$ and $C_{2}$ are the volume and the counting rate at the end of the measuring period. Collateral inflow is represented by the equation:

$$
\dot{Q}_{\text {inflow }}=\mathrm{V}_{2}-\mathrm{V}_{1}+\mathrm{Q}_{\text {outflow }}
$$

The femoral arterial pressure was monitored by a mercury manometer and the central venous pressure

${ }^{1}$ New Electronic Products Ltd., London. by a water manometer. Systemic arterial pressure was controlled by a blood reservoir maintained at a known height above the operating table and connected to one of the carotid arteries.

Collateral flow was recorded at three- to fiveminute intervals at constant pressures in the femoral artery, pulmonary artery, and pulmonary vein. Finally, the dog was killed and a necropsy was performed. In seven dogs the pulmonary vessels were injected with a $\mathrm{BaSO}_{4}$ suspension, and serial radiographs were taken.

\section{RESULTS}

In seven dogs with stenosis of the main pulmonary artery of a severity just tolerated by the dogs (another three died with symptoms of heart failure weeks or even two months after operation), the development of collateral vessels was moderate compared with that in normal controls where collateral inflow rarely exceeds 4-5 ml./min./ $10 \mathrm{~g}$. dry lung (Heimburg et al., 1961). Shunt flow characteristics were similar to those seen in normal dogs, that is, the collateral inflow increases with the systemic arterial pressure if the pulmonary arterial and pulmonary venous pressures are kept constant. On the other hand, the collateral inflow is smaller the higher the pulmonary arterial pressure. Some data are given in the Table.

Collateral outflow from the circuit into the systemic circulation could not be demonstrated in any of the dogs studied, although pulmonary venous pressures were frequently increased to 20 or $25 \mathrm{~mm}$. Hg until pulmonary oedema finished the experiment. Radioactivity in the systemic circulation showed no significant increase at the end of the perfusion. This suggests that pulmonary stenosis does not affect anastomosis between the pulmonary and bronchial veins.

More severe stenosis may be produced by the constriction of only one pulmonary artery, as shown in two dogs with right pulmonary artery stenosis. Three months after operation neither of the dogs had developed right heart hypertrophy, and the right ventricular pressures were normal. The left pulmonary artery showed marked poststenotic dilatation. Macroscopically, the bronchial arteries to the right side of the lung showed increased diameters.

Extracorporeal circulation to the right lower lobe was established without difficulty because neither of the dogs had developed adhesions between the lung and the chest wall. Collateral flow was almost linearly related to systemic arterial pressures at constant pressures in the pulmonary artery and vein (Fig. 3).

Collateral inflow did not show any significant relation to pulmonary arterial pressure in these 
TABLE

MAGNITUDE OF BRONCHIAL COLLATERAL INFLOW IN SEVEN DOGS WITH CONSTRICTION OF THE MAIN PULMONARY ARTERY THREE TO FOUR MONTHS AFTER OPERATION

\begin{tabular}{|c|c|c|c|c|c|c|c|c|}
\hline $\begin{array}{l}\dot{0} \\
Z \\
00 \\
0\end{array}$ & 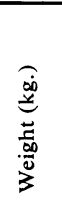 & 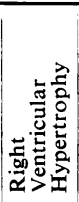 & 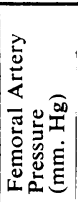 & 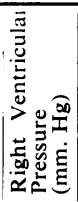 & 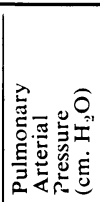 & 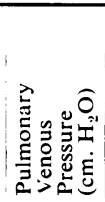 & 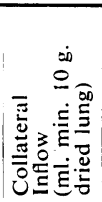 & 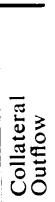 \\
\hline 67 & 18 & $+t$ & 90 & 1000 & $\begin{array}{l}40 \\
30 \\
20\end{array}$ & $\begin{array}{l}0 \\
0 \\
0\end{array}$ & $\begin{array}{r}4.4 \\
5.0 \\
11.0\end{array}$ & $\begin{array}{l}0 \\
0 \\
0\end{array}$ \\
\hline 87 & $15 \cdot 8$ & + & 90 & 682 & $\begin{array}{l}40 \\
20\end{array}$ & $\begin{array}{l}0 \\
0\end{array}$ & $\begin{array}{r}9.8 \\
14.7\end{array}$ & $\begin{array}{l}0 \\
0\end{array}$ \\
\hline 134 & $16 \cdot 7$ & + & 80 & 500 & $\begin{array}{l}40 \\
20\end{array}$ & $\begin{array}{l}0 \\
0\end{array}$ & $\begin{array}{l}3 \cdot 3 \\
6 \cdot 1\end{array}$ & $\begin{array}{l}0 \\
0\end{array}$ \\
\hline 148 & 22.5 & + & 80 & $?$ & $\begin{array}{l}40 \\
20\end{array}$ & $\begin{array}{l}0 \\
0\end{array}$ & $\begin{array}{l}1 \cdot 4 \\
4 \cdot 3\end{array}$ & $\begin{array}{l}0 \\
0\end{array}$ \\
\hline 135 & $16 \cdot 3$ & ++ & 80 & 953 & $\begin{array}{l}40 \\
20\end{array}$ & $\begin{array}{l}0 \\
0\end{array}$ & $\begin{array}{r}7 \cdot 6 \\
20 \cdot 3\end{array}$ & $\begin{array}{l}0 \\
0\end{array}$ \\
\hline 136 & $10 \cdot 4$ & + & 80 & 754 & $\begin{array}{l}40 \\
20\end{array}$ & $\begin{array}{l}0 \\
0\end{array}$ & $\begin{array}{l}4 \cdot 8 \\
8 \cdot 0\end{array}$ & $\begin{array}{l}0 \\
0\end{array}$ \\
\hline 147 & $18 \cdot 2$ & + & 80 & $?$ & $\begin{array}{l}45 \\
20\end{array}$ & $\begin{array}{l}0 \\
0\end{array}$ & $\begin{array}{l}1.7 \\
6.0\end{array}$ & $\begin{array}{l}0 \\
0\end{array}$ \\
\hline
\end{tabular}

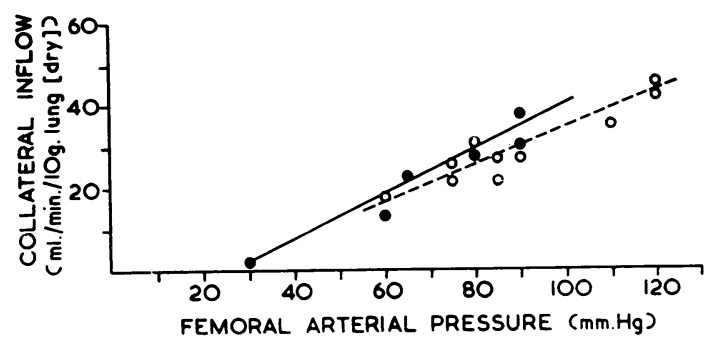

FIG. 3. Relation between collateral infiow and femoral arterial pressure in two dogs with constriction of the right pulmonary artery three months after operation. Pulmonary arterial pressure $30 \mathrm{~cm} . \mathrm{H}_{2} \mathrm{O}$, pulmonary venous pressure 0 . two dogs. This differs from the behaviour of $\overrightarrow{\overrightarrow{0}}$ bronchial shunt flow in normal dogs (Heimburg $\overrightarrow{0}$ et al., 1961). Apparently the resistance of the $\frac{}{0}$ dilated bronchial vessels varies widely with pressure, or most of the shunts are at capillary level rather than at the arterial side of the pulmonary circulation (Fig. 4).

Total or almost total occlusion of the pulmonary $\overrightarrow{0}$ artery of only one lobe is an extreme situation, $\vec{\overrightarrow{ }}$ which may occur in pulmonary embolism. In the two dogs studied with isolated constriction of the pulmonary artery of the right lower lobe, the bronchial arteries were maximally dilated with $\overrightarrow{0}$ diameters of up to $3 \mathrm{~mm}$. in life. A dense network of these dilated and tortuous arteries was found at the hilus of the lobe. There were spider-like telangiectases on the surface of the lobe, similar to those frequently found in patients with Fallot's tetralogy. An additional source of blood supply came from thin-walled vessels, which arose singly from adjacent lobes whose arteries had not been constricted. After crossing the interlobar space, they spread over the surface of the lobe while dividing into finer and finer branches.

Since cannulation of the pulmonary artery was impossible, only venous drainage at different aortic pressures was recorded. The linear relation between collateral inflow and pressure in the femoral artery is shown in Figure 5. Three months after operation revascularization may provide two-thirds of the normal pulmonary circulation in a dog with a ligated pulmonary artery. The revascularization of a lobe with a blocked pulmonary artery is demonstrated in Figure 6. The aorta was injected retrogradely with $\mathrm{BaSO}_{4}$ suspension. The heart was removed, but the lung was left in place. The bronchi of the right lower lobe are visible because of the dilated bronchial arterial network.

\section{DISCUSSION}

A decreased pulmonary circulation is always followed by an increased bronchial collateral flow. After experimental stenosis of the pulmonary artery in dogs, the development of bronchial arteries and bronchial collaterals becomes increasingly impressive with more severe stenosis. Williams and Towbin (1955) were able to demonstrate a good relation between bronchial collateral flow and the time after ligation of the left pulmonary artery. Liebow, Hales, Bloomer, Harrison, and Lindskog (1950) studied the anatomical changes after ligation of the pulmonary artery and found a great development of bronchial arteries and arterial collateral vessels. After nine months, 


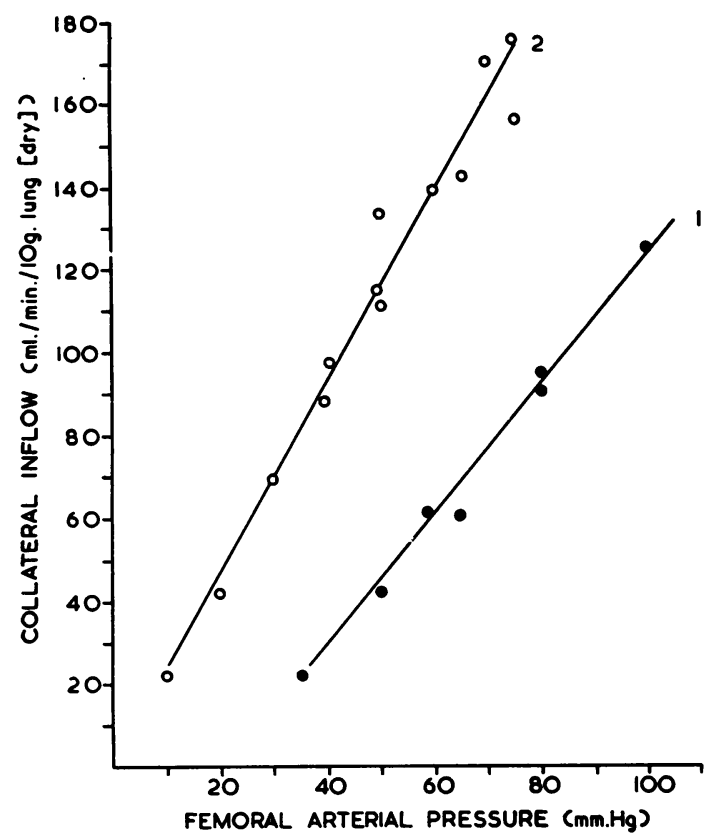

FIG. 5. Linear relation between bronchal collateral in . flow and femoral arterial pressure in two dogs with constricted pulmonary artery of the right lower lobe three months after operation. Almost total occlusion (1) and total occlusion (2).

precapillary shunts of $50 \mu$ diameter were observed, but severe histological changes of the lung tissue were absent.

It seems remarkable that in severe stenosis of the main pulmonary artery the collateral flow is only moderately increased or even normal. This is probably due to the fact that the pulmonary circulation is hardly affected by this type of stenosis. An increased resistance is compensated by hypertrophy of the right ventricle and a raised right ventricular pressure, while the cardiac output remains approximately normal. This seems to apply to humans also, for, according to Bishop, the development of collateral vessels does not occur to a significant degree unless more than two-thirds of the lumen of the main pulmonary artery is occluded. Unfortunately, the heart of the dog is highly vulnerable, so that more severe stenosis is not easily tolerated.

If, however, only. one pulmonary artery is stenosed, the haemodynamical consequences are different. None of the four dogs investigated with stenosis of the right pulmonary artery or the artery to the right lower lobe showed any right ventricular hypertrophy later. The main pul- monary artery pressure remains about normal apparently because blood flow to the left side of the lung increases. Necessarily, blood flow through the stenosed lung is reduced, and the post-stenotic pressure drops. One may argue whether a change of flow or pressure causes the development of collateral vessels since neither can be altered independently. We know that a low pulmonary arterial pressure is immediately followed by an increased shunt flow in normal dogs (Heimburg et al., 1961) simply because of the larger pressure difference between bronchial and pulmonary vessels. This could stimulate dilatation of preexisting anastomotic channels. On the other hand, a numerical increase of bronchial arteries cannot be explained by this hypothesis.

There is some evidence that at least the alveoli are supplied by the pulmonary vessels (Miller, 1947 ; von Hayek, 1953), although Cudkowicz, Abelmann, Levinson, Katznelson, and Jreissaty (1960) state that the nutrition of interstitial tissue of the alveolar walls comes to a certain extent from subpleural bronchial vessels via the interlobar septa. One may suggest, therefore, that hypoxia of the interstitial tissue occurs in pul-

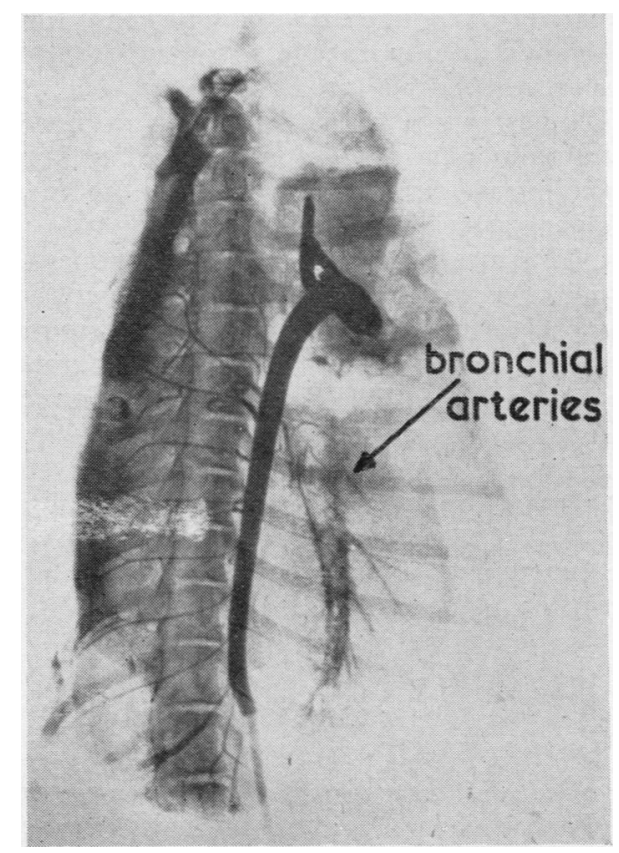

FIG. 6. Radiograph of the lungs of a dog with a stenosed pulmonary artery of the right lower lobe. The heart is removed and the aorta injected retrogradely with $\mathrm{BaSO}_{4}$ suspension. The bronchi of the right lower lobe are visible because of the dilated bronchial arteries. 
monary stenosis, which could stimulate bronchial collateral flow chemically. Oxygen consumption of the lung, however, is considered to be very small. Bostroem and Lochner (1955) showed that in isolated lungs $\mathrm{O}_{2}$ consumption is approximately $0.9 \mathrm{ml} . / \mathrm{min}$. $/ 10 \mathrm{~g}$. dry lung. It seems highly unlikely, therefore, that hypoxia of the lung tissue is possible as long as there is any pulmonary blood flow. After ligation of the pulmonary artery, moreover, bronchial collateral flow is so excessive that it easily exceeds the oxygen demand of the lung by more than 50 times. Considering that the normal pulmonary blood flow is about $300 \mathrm{ml} / \mathrm{min}$. $/ 10 \mathrm{~g}$. dry lung at normal pressures, it is remarkable that three months after ligation of one pulmonary artery the shunt flow is increased to about $200 \mathrm{ml}$./ min./10 g. dry lung at $85 \mathrm{~mm}$. Hg femoral arterial pressure. This indicates that hypoxia alone cannot be blamed for the increased collateral flow.

Haemodynamic changes, as mentioned, are not only limited to the stenosed part of the lung. In both dogs with pulmonary artery stenosis of one lobe only we observed a great number of thinwalled vessels, which developed from the lobes with a high pulmonary circulation to the lobe with a reduced pulmonary circulation. These vessels have a very characteristic pattern, and further investigation is necessary to show what type of collateral vessels they are.

The lung has a remarkable ability to restore the normal pulmonary circulation by the development of a collateral circulation, which in the case of pulmonary arterial stenosis leads to a left to right shunt. This means that even if the pulmonary circulation of a stenosed part of the lung is returned to almost normal after a few months, respiration is not restored, because the blood shunted is already arterialized. The development of bronchial collateral vessels is therefore in a way senseless as far as lung function is concerned. In cyanotic heart disease, however, this mechanism is of great importance; bronchial collateral vessels serve the same function as a Blalock anastomosis, and life may often depend on the magnitude of the bronchial collateral flow.

\section{SUMMARY}

The effect of experimental pulmonary artery stenosis on bronchial collateral flow was studied in dogs with a constricted main pulmonary artery and in dogs with a constricted pulmonary artery of $\stackrel{\overrightarrow{\vec{S}}}{\vec{\theta}}$ one side or of one lobe only.

Collateral flow to the lung increased only slightly in the dogs with stenosis of the main pul- $\frac{\bar{\sigma}}{\vec{D}}$ monary artery.

In dogs with stenosis of a similar severity of the right pulmonary artery a more marked increase in $\rightarrow$ the collateral flow was observed.

In pulmonary arterial stenosis of a single lobe, $\overrightarrow{\vec{\omega}}$ a great development of collateral vessels was found in which not only the bronchial vessels of the $\vec{x}$ stenosed lobe but also the vessels of other lobes were involved. After ligation of the pulmonary artery, collateral flow can provide two-thirds of $\dot{\omega}$ the normal pulmonary circulation three months 8 after operation.

I wish to thank Miss Mavis Murphy and Mr. J. $\vec{c}$ Robson for their technical assistance. I am grateful to Dr. M. Bishop and Dr. D. G. Melrose for their interest and support.

\section{REFERENCES}

Berry, J. L., and Daly, I. de Burgh (1931). The relation between the pulmonary and bronchial vascular systems. Proc. roy. Soc. B, $109,319$.

Bostroem, B., and Lochner, W. (1955). Utber den Sauerstoffverbrauch der Lunge. Pfiügers Arch. ges. Physiol., $260,511$.

Bruner, H. D., and Schmidt, C. F. (1947). Blood flow in the bronchial 은 artery of the anesthetized dog. Amer. J. Physiol., 148, 648 .

Cudkowicz, L., Abelmann, W. H., Levinson, G. E., Katznelson, G., and Jreissaty, R. M. (1960). Bronchial arterial blood flow. Clin. $\overrightarrow{\bar{O}}$ Sci., 19, 1.

Ferguson, C. F., Kobilak, R. E., and Deitrick, J. E. (1944). Varices 3 of the bronchial veins as a source of hemoptysis in mitral stenosis. Amer. Heart $J, 28,445$. Amer. Heart J., 28, 445.

Florange, W. (1960). Anatomie und Pathologie der Arteria bron-O chialis. Ergebn. allg. Path. path. Anat., 39, 152.

Hayek, H. von (1953). Die menschliche Lunge. Springer, Berlin.

Heimburg, P., Ochwadt, B., and Schoedel, W. (1961). Uber die Durchblutung broncho-pulmonaler Gefässverbindungen. Pflügers Arch. ges. Physiol., 273, 264.

Liebow, A. A. (1953). The bronchopulmonary venous collateral circulation with special reference to emphysema. Amer.J.Path., $29,251$.

- Hales, M. R., Bloomer, W. E., Harrison, W., and Lindskog, G. E. (1950). Studies on the lung after ligation of the pulmonary

artery. Ibid., 26, 177. and Lindskog, G. E. (1949). Enlargement of the bronchial arteries, and their anstomoses with the pulmonary arteries in 0 bronchiectasis. Ibid., 25, 211.

Marchand, P., Gilroy, J. C., and Wilson, V. H. (1950). An anatomical D study of the bronchial vascular system and its variations in 0 disease. Thorax, 5, 207.

Miller, W. S. (1947). The Lung, 2nd ed. Thomas, Springfield, Illinois.

Mollison, P. L., and Veall, N. (1955). The use of the isotope ${ }^{81} \mathrm{Cr}$ as a $\mathrm{O}$ label for red cells. Brit. J. Haemat., 1, 62.

Salisbury, P. F., Weil, P., and State, D. (1957). Factors influencing N collateral blood flow to the dog's lung. Circulat. Res., 5, 303.

Schoedel, W., Baltzer, G., Gade, G., and Piiper, J. (1961). Uber die N Durchblutung prä- und postcapillarer Verbindungen zwischen $\omega$ Bronchial- und Pulmonalgefässsystem. Pfiügers Arch. ges. Physiol., 273, 272.

and Heimburg, P. (1962). Die funktionelle Bedeutung dere broncho-pulmonalen Gefässverbindungen. Z. Kreislauff., 51,515 . Schoenmackers, J. (1960). Uber Bronchialvenen und ihre Stellung zwischen grossem und kleinem Kraislauf. Arch. Kreislauff., 32, 1. I (1963). Uber das 'arterio-venose' Schaltsystem im kleinen Kreislauf. Z. Kreislouff., 52, 313.

Williams, M. H., and Towbin, E. J. (1955). Magnitude and time of $\bar{O}$ development of the collateral circulation to the lung after occlu- $\stackrel{\vec{D}}{\mathrm{a}}$ sion of the left pulmonary artery. Circulat. Res., 3, 422. 